\title{
Serum response factor enhances liver metastasis of colorectal carcinoma via alteration of the E-cadherin/ß-catenin complex
}

\author{
HA NA CHOI ${ }^{1}$, KYUNG RYOUL KIM ${ }^{1}$, JI HYUN LEE ${ }^{1}$, HO SUNG PARK ${ }^{1}$, KYU YUN JANG $^{1}$, \\ MYOUNG JA CHUNG ${ }^{1}$, SI EUN HWANG ${ }^{2}$, HEE CHUL YU ${ }^{2}$ and WOO SUNG MOON ${ }^{1}$ \\ Departments of ${ }^{1}$ Pathology and ${ }^{2}$ Surgery, Medical School and Institute for Medical Sciences, \\ Chonbuk National University, Jeonju, Jeonbuk 561-756, Korea
}

Received August 7, 2008; Accepted September 9, 2008

DOI: $10.3892 /$ or_00000189

\begin{abstract}
Serum response factor (SRF) is a transcription factor that controls cell growth, differentiation, and tumor progression as well as muscle development and function. Reduced expression of cell adhesion molecules has been reported to be associated with tumor metastasis. The aim of this study was to evaluate the expression and a role of SRF in liver metastasis of primary colorectal carcinomas. We examined the expression of SRF, E-cadherin, and B-catenin by the use of immunochemical staining in 43 cases as a set of primary colorectal carcinomas and liver metastases. We also examined the role of SRF in colorectal carcinoma by overexpression of SRF in a colon cancer cell line. In metastatic carcinoma surgical samples, there was a marked increased expression of SRF as compared to expression in primary colorectal carcinoma surgical samples $(\mathrm{P}<0.05)$. E-cadherin expression was significantly decreased in metastatic liver carcinoma samples as compared to primary colorectal carcinoma samples $(\mathrm{P}<0.001)$. Frequent nuclear translocation of $\beta$-catenin protein in primary and metastatic carcinoma cells was observed. Overexpression of SRF in SW480 cells resulted in a decreased expression of E-cadherin and an increased expression of non-phosphorylated nuclear ß-catenin. Overexpression of SRF in colorectal carcinoma cells enhanced cell motility and invasiveness. These results indicate that overexpression of SRF in colorectal carcinoma cells is associated with modulation of E-cadherin/ß-catenin expression and may play an important role in colorectal cancer metastasis.
\end{abstract}

\section{Introduction}

Colorectal cancer (CRC) is one of the most common malignant neoplasms worldwide with an estimated 153,000

Correspondence to: Dr Woo Sung Moon, Department of Pathology, Chonbuk National University, Medical School, Jeonju, Jeonbuk 561-756, Korea

E-mail: mws@chonbuk.ac.kr

Key words: colorectal carcinoma, serum response factor, liver metastasis new cases and 52,000 deaths each year in the USA (1). Despite recent advances in diagnostic and therapeutic measures, the prognosis of CRC patients with a distant metastasis remains poor. Among CRC patients, $\sim 30 \%$ had a liver metastasis during the 5 years following diagnosis $(14.5 \%$ of the patients had a synchronous event and $14.5 \%$ of the patients had a metachronous event), with liver metastasis the major cause of therapeutic failure in CRC patients (2). Therefore, it is necessary to clarify the molecular mechanism(s) involved in liver metastasis and to identify the specific tumor metastasisassociated genes or proteins responsible for CRC metastasis.

Deterioration of cell-cell and cell-extracellular matrix (ECM) adhesions is often observed in tumor cells, which may be associated with invasion of cells into the surrounding tissues and blood vessels and causing metastatic spread (3). Epithelial cadherin (E-cadherin) is thought to mediate cellcell adhesion and the protein plays a critical role in cancer invasion and metastasis $(3,4)$. The intracellular domain of E-cadherin is found in a complex with other submembraneous cytosolic proteins such as $\alpha$-catenin and $\beta$-catenin, and these catenins mediate the connection of E-cadherin to actin filaments (5). Altered expression of the E-cadherin/Bcatenin complex is found associated with de-differentiation, invasion, and metastasis of CRCs (6-8). $\beta$-catenin binds to the protein expressed by the adenomatous polyposis coli (APC) tumor suppressor gene, and disruption of this complex is a crucial step in colorectal carcinogenesis $(9,10)$. Mutations in APC and B-catenin genes induce cytoplasmic or nuclear expression of $\beta$-catenin (11). Cytoplasmic or nuclear expression of $\beta$-catenin has been shown to have an important role in colorectal carcinogenesis, invasion, and metastasis $(6,11,12)$.

Serum response factor (SRF) is a transcription factor of the MADS box family $(13,14)$. To date, DNA binding sites for SRF [serum response elements (SREs)] have been found in the promoters of $\sim 50$ different genes, including immediate early genes like $c$-fos and $E g r-1$ and muscle-specific genes (15-17). Studies have also shown that SRF is involved in various cellular processes such as expression of immediate early and tissue-specific genes, cell proliferation, differentiation, and apoptosis (18-22). A recent study has demonstrated that SRF plays a role in tumor progression, specifically in the mesenchymal transition of epithelial tumor cells (23). We have also reported that expression of SRF is 
correlated with tumor cell de-differentiation and enhances cell motility and invasiveness in hepatocellular carcinoma (HCC) cells (24). However, expression of SRF in CRC and its role on the possible modulation of the E-cadherin/ß-catenin complex have not been investigated.

In the present study, we examined i) expression of SRF, E-cadherin and $\beta$-catenin in primary CRC and the corresponding metastatic CRC surgical specimens. ii) We examined if overexpression of SRF in a colon cancer cell line can alter expression of the E-cadherin/ß-catenin complex. iii) We also examined the role of SRF in migration and invasion of colon cancer cells.

\section{Materials and methods}

Patients and specimens. This study was approved by the Human Ethics Committee of Chonbuk National University Medical School. Forty-three cases of CRC with liver metastasis were evaluated from data of the surgical pathology medical records of the Department of Pathology at Chonbuk National University Hospital. The inclusion criteria were a histopathological diagnosis of an invasive CRC with paired metastatic tumors in the liver, the availability of clinical data, and the availability of paraffinembedded tissue specimens. All of the patients had undergone surgery and did not receive either chemotherapy or radiotherapy before surgical resection. CRC specimens were reviewed using morphological criteria according to the WHO classification of CRC. Table I shows the main characteristics of the primary tumors. Twenty-three patients were diagnosed with a lymph node metastasis, and 29 patients were diagnosed with a synchronous liver metastasis.

Colon cancer cell lines. The human colon cancer cell lines SW480 and LoVo were purchased from the Korean Cell Line Bank (Seoul, Korea). The SW480 and LoVo cell lines were cultured according to the recommendations of the cell banks.

Immunohistochemical analysis. For immunohistochemical staining of tissue samples, the Dako Envision system, which uses dextran polymers conjugated with horseradish peroxidase (Dako, Carpinteria, CA, USA), was performed as described previously (24). The sections were incubated for $2 \mathrm{~h}$ at room temperature with anti-SRF (1:100, Santa Cruz Biotechnology, Santa Cruz, CA, USA), anti-E-cadherin and anti- $\beta$-catenin (1:100, BD Biosciences, San Jose, CA, USA). Peroxidase activity was detected with the enzyme substrate 3-amino-9-ethyl carbazole. For negative control samples, the sections were treated the same way except that they were incubated with Tris-buffered saline without the use of a primary antibody.

Interpretation of SRF, $\beta$-catenin, and E-cadherin immunoreactivity. Two independent pathologists who had no knowledge of the histopathological data scored expression of SRF, B-catenin, and E-cadherin in the primary tumors and metastatic foci, and a high level of concordance (95\%) was achieved. The samples that were subjected to immunostaining with antibodies were rated according to a score calculated by
Table I. Clinicopathological characteristics.

Number of patients $(\%)$, $n=43$

$\begin{array}{lc}\begin{array}{l}\text { Age }(\text { yrs. }) \\ (\text { mean } \pm \text { SE) }\end{array} & 61.9 \pm 1.6 \text { (range, } \\ \text { Gender } & \\ \text { Male } & 26(60.5) \\ \text { Female } & 17(39.5) \\ \text { Tumor location } & \\ \text { Ascending } & 10(23.3) \\ \text { Transverse } & 2(4.7) \\ \text { Descending } & 3(7.0) \\ \text { Recto-sigmoid } & 28(65.1) \\ \text { Differentiation } & \\ \text { Well } & 2(4.7) \\ \text { Moderate } & 38(88.4) \\ \text { Poorly } & 2(4.7) \\ \text { Mucinous } & 1(2.3)\end{array}$

Lymph node metastasis

Absent

Present

No biopsy

Depth of invasion

Muscle

Subserosa

Serosa

$4(9.3)$

multiplying the intensity of the stain to the area of the stain. The intensity of cell staining was graded according to the following scale: 0 , no staining; $1+$, mild staining; $2+$, moderate staining; $3+$ strong staining. The area of staining was evaluated using the following scale: $0,<10 \%$ of the cells stained positive; $1+, 10-30 \%$ of the cells stained positive; $2+$, $31-70 \%$ of the cells stained positive; $3+,>71 \%$ of the cells stained positive. The maximum combined score was 9 and the minimum score was zero. Membranous E-cadherin and B-catenin were assessed. Nuclear or cytoplasmic signals of ß-catenin were also evaluated independently. Clear nuclear SRF staining in more than $10 \%$ of the tumor cells was defined as SRF positive.

Transfection of SRF complementary DNA. Human SRF complementary DNA (cDNA) (accession number: J03161) was cloned into pcDNA3 (Invitrogen, Carlsbad, CA, USA). The same plasmid without an SRF insert was used as a control vector. All plasmids were amplified in DH5 $\alpha$ Escherichia coli competent cells (Invitrogen) and were purified using an endo-free plasmid mega-prep kit (Qiagen, Valencia, CA, USA). Transient transfection of SW480 cells with human SRF or vector cDNA was performed using LipofectAmin (Gibco BRL, Gaithersburg, MD, USA). 


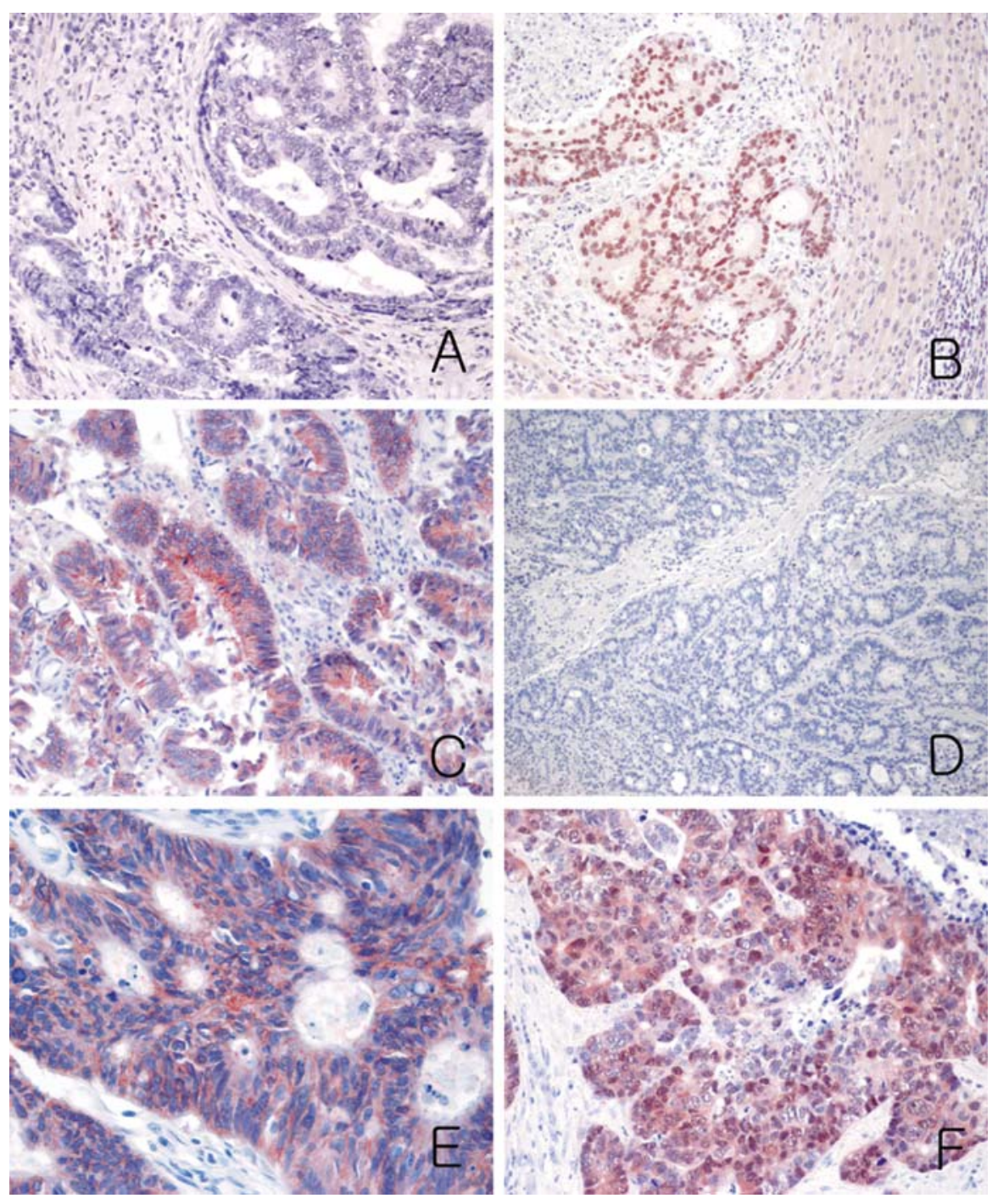

Figure 1. Representative sections of molecular expression. (A) A primary tumor sample showed no immunoreactivity for serum response factor (SRF). (B) Strong nuclear expression of SRF in a liver metastasis sample. (C) Membranous expression of E-cadherin in a primary colorectal carcinoma (CRC). (D) Loss of E-cadherin expression in a liver metastasis. (E) Membranous expression of ß-catenin in a primary colorectal carcinoma. (F) Nuclear expression of $ß$-catenin in a liver metastasis.

Western blots. Cells were homogenized in a lysis buffer (50 mM Tris, pH 7.5, $150 \mathrm{mM} \mathrm{NaCl,} \mathrm{0.5 \%} \mathrm{Nonidet} \mathrm{P-40)}$ containing $1 \mathrm{mM}$ phenylmethylsulfonyl fluoride, $2 \mu \mathrm{g} / \mathrm{ml}$ leupeptin, $2 \mu \mathrm{g} / \mathrm{ml}$ aprotinin, $5 \mathrm{mM}$ sodium fluoride, and $1 \mathrm{mM}$ sodium orthovanadate. The cell lysates were subjected to Western blotting as described previously (24). Since SRF is known to regulate expression of genes such as $c$-Fos and Egr-1, the expression levels of c-Fos and SRF were evaluated in an SRF-transfected SW480 cell line. To examine the effect of SRF overexpression on E-cadherin and $B$-catenin expression in HCC cells, antibodies against E-cadherin, $\beta$-catenin and dephospho- $\beta$-catenin (Upstate, Millipore, Lake Placid, NY, USA) were used as probes in SRF-transfected cells. Bound antibody signals were visualized by the use of a chemiluminescence system (Amersham Life Sciences, Arlington Heights, IL, USA). The membranes were stripped and reprobed with a monoclonal anti- $\beta$-actin antibody (Sigma, St. Louis, MO, USA) to normalize for protein loading. Quantification of the data was performed using ImageQuant software
(Molecular Dynamics, Piscataway, NJ, USA). Each signal was normalized against the corresponding $B$-actin signal.

In vitro assays of cell migration and invasion. The cell migration assay was performed using Transwell chambers as described previously (24). SW480 cells transfected with either the SRF expression plasmid or the control vector plasmid were serum starved for $48 \mathrm{~h}$. Transwell chambers equipped with $8 \mu \mathrm{m}$ Matrigel-coated filters (24-well format) (Becton Dickinson, Franklin Lakes, NJ, USA) were rehydrated, and $4 \times 10^{4}$ cells in $400 \mu 1$ of serum free DMEM were seeded in the upper chamber. DMEM containing 2 or $5 \%$ fetal bovine serum (FBS) was used in the lower chamber. After incubation for $12-22 \mathrm{~h}$ at $37^{\circ} \mathrm{C}$, cells on the upper surface of the filter were mechanically removed with a cotton swab. The filters were fixed and stained using a DiffQuick staining kit (Dade Behring, Newark, DE, USA). The cells on the lower surface of filters were counted under a light microscope at magnification, x100 in five randomly selected fields per well. The migration assay was also 
Table II. Expression patterns of serum response factor (SRF), E-cadherin, and $\beta$-catenin in primary and metastatic colorectal carcinoma.

\section{Primary tumor Liver metastasis}

(\%)

(\%)

\begin{tabular}{lcc}
\hline SRF & & \\
Nuclear & $16(37)$ & $26(60)$ \\
Negative & $27(63)$ & $17(40)$ \\
E-cadherin & & \\
Membrane & $37(86)$ & $26(60)$ \\
Cytoplasm and/or nucleus & $1(2)$ & $3(7)$ \\
Negative & $5(12)$ & $14(33)$ \\
ß-catenin & & \\
Cytoplasm and/or nucleus & $24(56)$ & $20(47)$ \\
Cytoplasm only & $4(9)$ & $3(7)$ \\
Cytoplasm and/or membrane & $9(21)$ & $12(28)$ \\
Negative & $6(14)$ & $8(18)$ \\
\hline
\end{tabular}

Table III. Immunohistochemical analysis of the expression of SRF and E-cadherin in primary and metastatic colorectal carcinoma.

\begin{tabular}{lcc}
\hline & \multicolumn{2}{c}{$\begin{array}{c}\text { Immohistochemical scoring } \\
(\text { mean } \pm \text { SE) }\end{array}$} \\
\cline { 2 - 3 } & SRF & E-cadherin \\
\hline Primary colorectal carcinoma & $1.51 \pm 0.41$ & $6.47 \pm 0.48$ \\
Liver metastasis & $2.98 \pm 0.53$ & $4.0 \pm 0.47$ \\
P-value & 0.033 & $<0.001$ \\
\hline
\end{tabular}

Statistical analysis performed by use of the Mann-Whitney U test.

performed with Transwell chambers where the filters were not coated with Matrigel using the same procedure.

Statistical analysis. Data are expressed as means \pm SE. The differences in the numerical data between primary CRC and metastatic foci were evaluated by use of the Mann-Whitney $\mathrm{U}$ test. Comparisons between groups were performed using the Student's t-test for the migration and invasion assays. A $\mathrm{P}$-value $<0.05$ was considered as statistically significant.

\section{Results}

Expression of SRF, E-cadherin, and $\beta$-catenin in primary $C R C$. We initially assessed the expressions of SRF, E-cadherin, and $B$-catenin in cancer cells and adjacent normal epithelial cells of the same patient. SRF was not detected in normal epithelial cells whereas nuclear expression of SRF was detected in 16 (37\%) out of 43 tumor samples examined. Normal epithelial cells always strongly expressed Ecadherin and $\beta$-catenin at the basolateral cell membrane, and
Table IV. Comparison of the immunoreactive scores of SRF, E-cadherin, and $\beta$-catenin Between primary colorectal carcinoma and liver metastasis.

\begin{tabular}{lc}
\hline Immunoreactive score & No. of cases \\
\hline SRF & 4 \\
Primary carcinoma $>$ Liver metastasis & 7 \\
Primary carcinoma = Liver metastasis & 16 \\
Primary carcinoma < Liver metastasis & \\
E-cadherin & 27 \\
Primary carcinoma > Liver metastasis & 3 \\
Primary carcinoma = Liver metastasis & 12 \\
Primary carcinoma < Liver metastasis & \\
B-catenin & \\
Membrane staining & 7 \\
Primary carcinoma & 3 \\
Liver metastasis & \\
Nuclear and/or cytoplasmic translocation & 30 \\
$\quad$ Primary carcinoma & 32 \\
Liver metastasis &
\end{tabular}

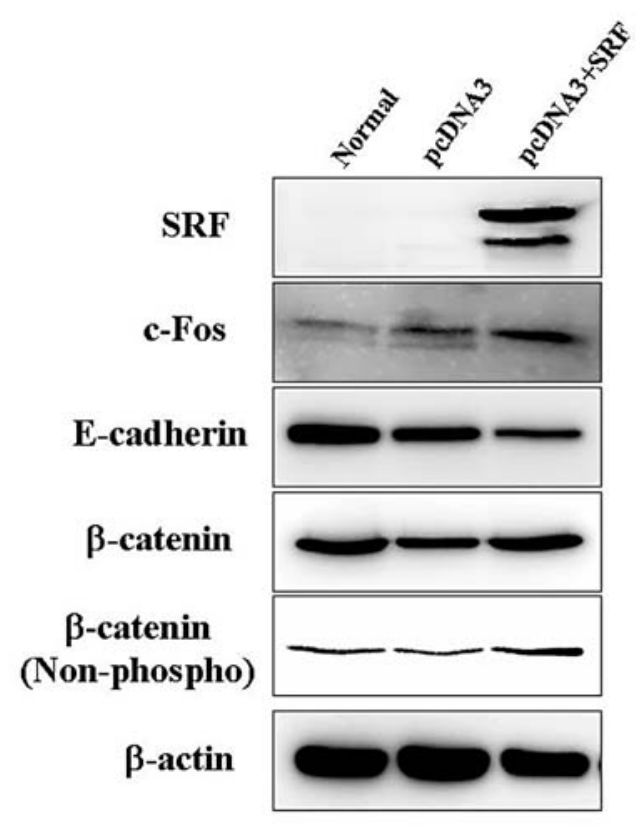

Figure 2. Western blot analysis. Enhanced expression of SRF, c-Fos, and non-phospho, nuclear ß-catenin in SW480 cells transfected with the SRF gene. Overexpression of SRF resulted in a decrease in the expression level of E-cadherin as compared to the expression level determined in control cells.

no cytoplasmic or nuclear staining was detectable (Fig. 1). In primary CRC samples, nuclear translocation of B-catenin was detected in $24(56 \%)$ tumors, and loss of membranous expression of E-cadherin was detected in 6 (14\%) tumors. The results are summarized in Table II. 
A

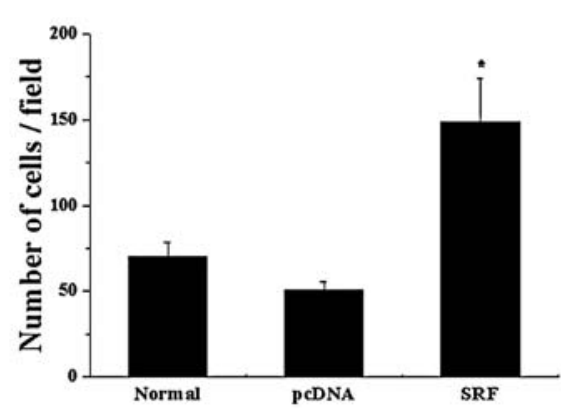

B

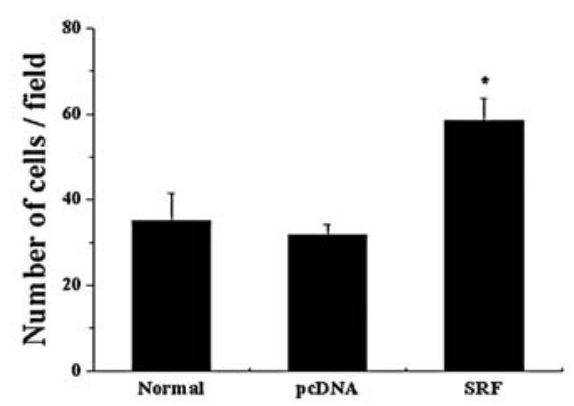

Figure 3. In vitro cell migration and invasion assay. (A) In the SRFtransfected SW480 cells, cell migration was increased by 2.5 -fold when compared with those of control. (B) SRF-transfected SW480 cell invasion was increased by 1.7 -fold when compared with those of control. The experiment was independently repeated 3 times $(\mathrm{p}<0.01)$.

Expression of SRF, E-cadherin, and $\beta$-catenin in metastatic foci. In metastatic CRC lesions, high nuclear expression of SRF in tumor cells was detected in $26(60 \%)$ samples. Loss of membranous E-cadherin expression was observed in 14 (33\%) tumor samples (Table II). The mean scores for immunohistochemical staining of SRF and E-cadherin from 43 metastatic liver samples were significantly different from the scores for samples from primary tumors (Table III). The expression level of SRF in the metastatic liver samples increased in $16(37 \%)$ tumors while expression levels of Ecadherin in the metastatic liver samples decreased in 27 $(63 \%)$ tumors (Table IV). However, the spatial expression of ß-catenin from metastatic livers was not significantly different from that of the primary tumors.

SRF expression in CRC cell lines. To verify the above observations that SRF is expressed in CRC cells, we examined SRF expression levels in the SW480 and LoVo cell lines. Although SRF was expressed in the two cell lines, expression levels were very low.

Overexpression of SRF modulates expression of E-cadherin and $\beta$-catenin. We analyzed the expression levels of SRF and an SRF target gene, $c$-Fos, in the SRF-transfected SW480 cells by the use of Western blotting. In SRF-transfected SW480 cells, expression levels of SRF and c-Fos increased by 3.5 -fold and 1.5-fold, respectively (Fig. 2). Overexpression of SRF in SW480 cells resulted in a 2.3 -fold decreased expression level of E-cadherin. Overexpression of SRF did not alter the total expression level of $B$-catenin (Fig. 2). However, expression of dephospho- $\beta$-catenin, which recognizes activated nuclear $\beta$-catenin (25), increased by 1.4-fold.

SRF increases HCC cell migration and invasion. To determine the role of SRF in SW400 cell migration and invasion, we performed a cell migration and invasion assay. Overexpression of SRF in SW400 cells increased cell migration by 2.5 -fold as compared to migration in a control cell line (Fig. 3A). Overexpression of SRF also increased cell invasion by 1.7 -fold as compared to migration in a control cell line (Fig. 3B).

\section{Discussion}

SRF is a widely expressed transcription factor that plays an important role in cellular differentiation and cell cycle regulation (15-22). However, the role of SRF in cancer is not well understood. This study has demonstrated for the first time the following findings. i) Increased expression of $\mathrm{SRF}$ in liver metastasis was seen as compared to expression in primary CRC. ii) Loss of membranous E-cadherin and accumulation of nuclear B-catenin was associated with liver metastasis of CRC. iii) Overexpression of SRF in CRC cells was associated with decreased expression of E-cadherin but an increased level of nuclear (dephospho-) ß-catenin. iv) Overexpression of SRF in CRC cells promotes cell migration and invasion. These findings show that overexpression of $\mathrm{SRF}$ in CRC cells plays a crucial role in tumor progression and liver metastasis of CRC. Our study also provided evidence that overexpression of SRF enhances cell motility and invasiveness of CRC cells through the modulation of the E-cadherin/ß-catenin complex. These observations are in agreement with a previous study demonstrating that SRF has an important role in tumor progression, specifically for the transition to the invasive metastatic stage of carcinogenesis (23). Furthermore, overexpression of SRF in hepatocellular carcinoma cells accelerates migration and invasion with subsequent acquisition of a mesenchymal phenotype by expression of a mesenchymal marker, vimentin, and activation of immediate early genes (24). Phiel et al have shown that the nuclear accessibility of SRF is different in smooth muscle vs. smooth muscle cells undergoing neoplastic transformation (26). SRF is highly expressed in pulmonary lymphangioleiomyomatosis (LAM) cells and the high SRF level in LAM may contribute to extracellular matrix degradation and progressive LAN cell infiltration of the lung (27). SRF is a nuclear repressor of TGF- $\beta$ signaling and suppresses TGF- $\beta$-induced cell growth inhibitory activity by blocking the transcriptional activity of the Smad complex (28). SRF also is an important determinant of androgen receptor action in prostatic cancer cells and loss of SRF suppresses proliferation of prostatic cancer cells (29). Our findings, together with the findings in previous studies, suggest a potential role of SRF in cancer cell growth and metastasis.

Emerging evidence suggests that altered expression of the E-cadherin/ß-catenin complex is associated with dedifferentiation, invasion, and metastasis, and therefore 
expression of the complex is suggested as a potential prognostic factor in CRC $(6-8,11,12)$. In the present study, loss of membranous E-cadherin and frequent accumulation of nuclear $\beta$-catenin are associated with liver metastasis of CRC. These findings are consistent with previous reports indicating that nuclear staining for $\beta$-catenin and loss of membranous E-cadherin have important roles in CRC invasion and metastasis $(6,7,30,31)$. However, this issue remains somewhat controversial. Roca et al have reported that $\beta$-catenin expression or accumulation in the nucleus did not correlate with survival of CRC patients (32). Another study has shown increased expression of the E-cadherin/ßcatenin complex in metastatic lymph nodes and in liver tumors as compared with the expression of the complex in primary CRC tumors (8). Bongiorono et al have reported that tumor cells lost E-cadherin transiently to metastasize, Ecadherin is then re-expressed at a distant metastatic site in esophageal and lung cancer (33). These findings suggest that increased expression of adhesion molecules in tumor cells after release from the primary site may be important and perhaps necessary for tumor cells to adhere in remote organs (8). The differential expression pattern and biological significance of the E-cadherin/catenin complex in primary $\mathrm{CRC}$ and metastatic lesions remains largely unknown, the role of the complex and should be investigated.

In this study, we also found that overexpression of SRF in CRC cells decreased expression of E-cadherin and increased nuclear (dephospho-) B-catenin expression. Furthermore, overexpression of SRF in CRC promoted cell migration and invasion in vitro. Our findings suggest that SRF over-expression could induce epithelial mesenchymal transition via down-regulation of E-cadherin with accumulation of nuclear $\beta$-catenin, contributing to the invasive and metastatic potential of CRC. The association between SRF overexpression and increased nuclear translocation of $\beta$-catenin found in our study may be of importance as $\beta$-catenin signaling is strongly linked to colorectal carcinogenesis (9-11). B-catenin is involved in the Wnt signaling pathway, activating the transcription of crucial target genes responsible for cellular proliferation and differentiation (9-11,34). An association between SRF expression and alteration of the E-cadherin/ß-catenin complex in human cancer, to the best of our knowledge, has not been reported previously. The mechanism(s) by which $\mathrm{SRF}$ induces the accumulation of $\beta$-catenin in the nucleus is not clearly understood. However, accumulation of B-catenin in the nucleus induced by SRF may promote an association with TCF/LEF transcription factors and affect the transcription of proteins such as cyclin D1 and c-myc that are regulated by $\beta$-catenin $(9,11,34)$. $\beta$-catenin also controls E-cadherin-mediated cell adhesion at the plasma membrane and mediates the interplay of adherence junction molecules with the actin cytoskeleton $(5,34)$. Down-regulation of Ecadherin with accumulation of nuclear B-catenin of human $\mathrm{CRC}$ induced by overexpression of SRF as demonstrated in this study leads to the loss of cell-cell adhesion and to increased transcription of Wnt target genes and is closely correlated with colon cancer progression $(34,35)$.

In conclusion, this study indicates that increased expression of SRF and loss of membranous E-cadherin are closely associated with liver metastasis of CRC. Furthermore, SRF appears to modulate E-cadherin/ß-catenin expression in $\mathrm{CRC}$ cells, which may enhance cell motility and invasiveness of CRC cells.

\section{Acknowledgements}

This work was supported by the Korea Research Foundation Grant funded by the Korean Government (MOEHRD) (The Regional Research Universities Program/Center for Healthcare Technology Development) and a grant of the Korea Health 21 $\mathrm{R}$ and D Project, Ministry of Health and Welfare, Republic of Korea (A06-0066-AA1018-06N1-00010A).

\section{References}

1. Jemal A, Siegel R, Ward E, Murray T, Xu J and Thun MJ: Cancer statistics, 2007. CA Cancer J Clin 57: 43-66, 2007.

2. Manfredi S, Lepage C, Hatem C, Coatmeur O, Faivre J and Bouvier AM: Epidemiology and management of liver metastases from colorectal cancer. Ann Surg 244: 254-259, 2006.

3. Rudmik LR and Magliocco AM: Molecular mechanisms of hepatic metastasis in colorectal cancer. J Surg Oncol 92: 347-359, 2005.

4. Guarino M, Rubino B and Ballabio G: The role of epithelialmesenchymal transition in cancer pathology. Pathology 39: 305-318, 2007.

5. Mège RM, Gavard J and Lambert M: Regulation of cell-cell junctions by the cytoskeleton. Curr Opin Cell Biol 18: 541-548, 2006.

6. Lugli A, Zlobec I, Minoo P, Baker K, Tornillo L, Terracciano L and Jass JR: Prognostic significance of the wnt signalling pathway molecules APC, beta-catenin and E-cadherin in colorectal cancer: a tissue microarray-based analysis. Histopathology 50: 453-464, 2007.

7. Fernebro E, Bendahl PO, Dictor M, Persson A, Fernö M and Nilbert M: Immunohistochemical patterns in rectal cancer: application of tissue microarray with prognostic correlations. Int J Cancer 111: 921-928, 2004.

8. Ikeguchi M, Makino M and Kaibara N: Clinical significance of E-cadherin-catenin complex expression in metastatic foci of colorectal carcinoma. J Surg Oncol 77: 201-207, 2001.

9. Rubinfeld B, Souza B, Albert I, Müller O, Chamberlain SH, Masiarz FR, Munemitsu S and Polakis P: Association of the APC gene product with beta-catenin. Science 262: 1731-1734, 1993.

10. Su LK, Vogelstein B and Kinzler KW: Association of the APC tumor suppressor protein with catenins. Science 262: 1734-1737, 1993.

11. Korinek V, Barker N, Morin PJ, van Wichen D, de Weger R, Kinzler KW, Vogelstein B and Clevers H: Constitutive transcriptional activation by a beta-catenin-Tcf complex in $\mathrm{APC}^{-/-}$colon carcinoma. Science 275: 1784-1787, 1997.

12. Wong SC, Lo ES, Chan AK, Lee KC and Hsiao WL: Nuclear beta catenin as a potential prognostic and diagnostic marker in patients with colorectal cancer from Hong Kong. Mol Pathol 56: 347-352, 2003

13. Treisman R: Identification of a protein-binding site that mediates transcriptional response of the c-fos gene to serum factors. Cell 46: 567-574, 1986.

14. Shore P and Sharrocks AD: The MADS-box family of transcription factors. Eur J Biochem 229: 1-3, 1995.

15. Norman C, Runswick M, Pollock R and Treisman R: Isolation and properties of cDNA clones encoding SRF, a transcription factor that binds to the c-fos serum response element. Cell 55: 989-1003, 1998.

16. Sobue K, Hayashi K and Nishida W: Expressional regulation of smooth muscle cell-specific genes in association with phenotypic modulation. Mol Cell Biochem 190: 105-118, 1999.

17. Chai $\mathbf{J}$ and Tarnawski AS: Serum response factor: discovery, biochemistry, biological roles and implications for tissue injury healing. J Physiol Pharmacol 53: 147-157, 2002. 
18. Schratt G, Weinhold B, Lundberg AS, Schuck S, Berger J, Schwarz H, Weinberg RA, Ruther U and Nordheim A: Serum response factor is required for immediate-early gene activation yet is dispensable for proliferation of embryonic stem cells. Mol Cell Biol 21: 2933-2943, 2001.

19. Camoretti-Mercado B, Liu HW, Halayko AJ, Forsythe SM, Kyle JW, Li B, Fu Y, McConville J, Kogut P, Vieira JE, Patel NM, Hershenson MB, Fuchs E, Sinha S, Miano JM, Parmacek MS, Burkhardt JK and Solway J: Physiological control of smooth muscle-specific gene expression through regulated nuclear translocation of serum response factor. J Biol Chem 275: 30387-30393, 2000.

20. Ding W, Gao S and Scott RE: Senescence represses the nuclear localization of the serum response factor and differentiation regulates its nuclear localization with lineage specificity. J Cell Sci 114: 1011-1018, 2001.

21. Bertolotto C, Ricci JE, Luciano F, Mari B, Chambard JC and Auberger P: Cleavage of the serum response factor during death receptor-induced apoptosis results in an inhibition of the c-FOS promoter transcriptional activity. J Biol Chem 275: 12941-12947, 2000.

22. Zhang X, Chai J, Azhar G, Sheridan P, Borras AM, Furr MC, Khrapko K, Lawitts J, Misra RP and Wei JY: Early postnatal cardiac changes and premature death in transgenic mice overexpressing a mutant form of serum response factor. J Biol Chem 276: 40033-40040, 2001

23. Psichari E, Balmain A, Plows D, Zoumpourlis V and Pintzas A: High activity of serum response factor in the mesenchymal transition of epithelial tumor cells is regulated by RhoA signaling. J Biol Chem 277: 29490-29495, 2002.

24. Park MY, Kim KR, Park HS, Park BH, Choi HN, Jang KY, Chung MJ, Kang MJ, Lee DG and Moon WS: Expression of the serum response factor in hepatocellular carcinoma: Implications for epithelial-mesenchymal transition. Int J Oncol 31: 1309-1315, 2007.

25. Schmelz EM, Roberts PC, Kustin EM, Lemonnier LA, Sullards MC, Dillehay DL and Merrill AH Jr: Modulation of intracellular beta-catenin localization and intestinal tumorigenesis in vivo and in vitro by sphingolipids. Cancer Res 61: 6723-6729, 2001.
26. Patten LC, Belaguli NS, Baek MJ, Fagan SP, Awad SS and Berger DH: Serum response factor is alternatively spliced in human colon cancer. J Surg Res 121: 92-100, 2004.

27. Zhe X, Yang Y and Schuger L: Imbalanced plasminogen system in lymphangioleiomyomatosis: potential role of serum response factor. Am J Respir Cell Mol Biol 32: 28-34, 2005.

28. Lee HJ, Yun CH, Lim SH, Kim BC, Baik KG, Kim JM, Kim WH and Kim SJ: SRF is a nuclear repressor of Smad3-mediated TGF-beta signaling. Oncogene 26: 173-185, 2007.

29. Heemers HV, Regan KM, Dehm SM and Tindall DJ: Androgen induction of the androgen receptor coactivator four and a half LIM domain protein-2: evidence for a role for serum response factor in prostate cancer. Cancer Res 67: 10592-10599, 2007.

30. Wong SC, Lo ES, Lee KC, Chan JK and Hsiao WL: Prognostic and diagnostic significance of beta-catenin nuclear immunostaining in colorectal cancer. Clin Cancer Res 10: 1401-1408, 2004.

31. Bravou V, Klironomos G, Papadaki E, Taraviras S and Varakis J: ILK over-expression in human colon cancer progression correlates with activation of beta-catenin, down-regulation of E-cadherin and activation of the Akt-FKHR pathway. J Pathol 208: 91-99, 2006.

32. Roca F, Mauro LV, Morandi A, Bonadeo F, Vaccaro C, Quintana GO, Specterman S, de Kier Joffé EB, Pallotta MG, Puricelli LI and Lastiri J: Prognostic value of E-cadherin, betacatenin, MMPs (7 and 9), and TIMPs (1 and 2) in patients with colorectal carcinoma. J Surg Oncol 93: 151-160, 2006.

33. Bongiorno PF, al-Kasspooles M, Lee SW, Rachwal WJ, Moore JH, Whyte RI, Orringer MB and Beer DG: E-cadherin expression in primary and metastatic thoracic neoplasms and in Barrett's oesophagus. Br J Cancer 71: 166-172, 1995.

34. Bienz $\mathrm{M}$ and Clevers $\mathrm{H}$ : Linking colorectal cancer to Wnt signaling. Cell 103: 311-320, 2000.

35. Brembeck FH, Rosário M and Birchmeier W: Balancing cell adhesion and Wnt signaling, the key role of beta-catenin. Curr Opin Genet Dev 16: 51-59, 2006. 